\title{
TIMING OF MID-TRIMESTER CERVICAL LENGTH SHORTENING IN HIGH-RISK WOMEN
}

\author{
Jeff M. Szychowski, PhD, John Owen, MD, MSPH, Gary Hankins, MD, Jay lams, MD, Jeanne \\ Sheffield, MD, Annette Perez-Delboy, MD, Vincenzo Berghella, MD, Deborah A. Wing, MD, \\ and Edward R. Guzman, MD \\ University of Alabama at Birmingham, Department of Biostatistics, Birmingham, Alabama \\ University of Alabama at Birmingham; Department of OB/GYN, Maternal-Fetal Division, \\ Birmingham, Alabama \\ University of Texas Medical Branch, Department of OB/GYN, Maternal-Fetal Division, Galveston, \\ Texas \\ The Ohio State University Medical Center, Department of OB/GYN, Maternal-Fetal Division, \\ Columbus, Ohio \\ The University of Texas Southwestern Medical Center, Department of OB/GYN, Maternal-Fetal \\ Division, Dallas, Texas \\ Columbia University Medical Center, Department of OB/GYN, Maternal-Fetal Division, New York, \\ New York \\ Jefferson Medical College of Thomas Jefferson University, Department of OB/GYN, Maternal- \\ Fetal Division, Philadelphia, Pennsylvania \\ University of California, Irvine, Department of OB/GYN, Maternal-Fetal Division, Orange, \\ California \\ Saint Peter's University Hospital, Department of Obstetrics and Gynecology, Maternal-Fetal \\ Medicine Division, New Brunswick, New Jersey and Drexel University School of Medicine, \\ Philadelphia, Pennsylvania
}

\section{Abstract}

Objective-To examine the natural history of cervical length shortening in women, who had experienced at least one prior spontaneous preterm birth at $17+0-33+6$ weeks' gestation.

Methods-Analysis of pre-randomization data from the multicenter Vaginal Ultrasound Cerclage Trial. Serial cervical length was measured by vaginal sonography in 1014 high-risk women at $16+0$ to $22+6$ weeks. We determined the time (in weeks' gestation) to cervical length shortening $<25 \mathrm{~mm}$, or censoring, either by entering the randomized cerclage trial or attaining 22 +6 weeks' gestation. The incidence of cervical length shortening and the time to shortening were compared for women whose earliest prior preterm birth was in the mid-trimester, defined as <24 weeks versus at weeks 24-33. Similar comparisons were done based on each patient's most recent birth history.

Address Correspondence to: John Owen, MD, MSPH, University of Alabama at Birmingham, $61919^{\text {th }}$ Street South, OHB 458, Birmingham, AL 35249-7333, Office: (205) 934-7343, Fax: (205) 975-9858, johnowen@uab.edu.

FOR THE VAGINAL ULTRASOUND CERCLAGE TRIAL CONSORTIUM

Formatted for Ultrasound in Obstetrics and Gynecology

This research was presented in abstract form at the 2006 meeting of the Society of Maternal-Fetal Medicine, Miami, Florida. 
Results-Time to cervical length shortening by survival analysis was significantly shorter (Hazard Ratio $[\mathrm{HR}]=2.2, \mathrm{p}<0.0001)$ and the relative risk $(\mathrm{RR})$ of shortening significantly higher $(\mathrm{RR}=1.8, \mathrm{p}<0.0001)$ for women whose earliest prior spontaneous preterm birth was $<24$ weeks. A larger effect was observed for women whose most recent birth was $<24$ weeks (HR $=2.8$, $\mathrm{p}<0.0001 ; \mathrm{RR}=2.1, \mathrm{p}<0.0001$ ). The observed hazard ratios remained significant after adjusting for confounders in a multivariable Cox proportional hazards model.

Conclusion-Women with a prior spontaneous preterm birth $<24$ weeks are at a higher risk of cervical shortening, and do so at a higher rate and at an earlier gestational age, than do women with a later preterm birth history.

\section{Keywords}

cervical length shortening; preterm birth; vaginal sonography; mid-trimester birth

\section{INTRODUCTION}

Preterm birth continues to be a common problem in the U.S. with increasing annual rates that have reached $12.8 \%$ in $2006^{1}$. Women with prior spontaneous preterm birth(s) have one of the strongest risk factors for subsequent preterm birth $^{2-4}$. In addition, cervical length shortening has been shown to increase the risk of spontaneous preterm birth in high-risk women with a prior spontaneous preterm birth $^{5-8}$. Moreover, the gestational age at prior preterm delivery is shown to be correlated with cervical length in a subsequent pregnancy ${ }^{9}$. However, little is known about the rate of cervical shortening in high-risk women with a prior spontaneous preterm birth. With a better understanding of the natural history and mechanisms leading to spontaneous preterm birth and cervical length shortening, improved prevention and intervention strategies will likely be developed. However, these mechanisms are complex and poorly understood ${ }^{10,11}$. With this aim we investigate the timing of midtrimester cervical length shortening in women at high risk for recurrent preterm birth.

\section{METHODS}

Pre-randomization data from the Vaginal Ultrasound Cerclage Trial was used for this secondary analysis. This is a recently completed, multi-center, randomized intervention trial designed to test whether cerclage prevents preterm birth in women with at least one prior spontaneous preterm birth between $17+0$ and $33+6$ weeks' gestation and shortened cervical length $<25 \mathrm{~mm}^{12}$. Trial details are available at:

http://www.clinicaltrials.gov/ct2/show/NCT00059683?term=cerclage\&rank=3. Consenting women who met the prior preterm birth inclusion criteria were enrolled into this trial approved by the Human Use Committees at all participating centers. Women enrolled in the observational phase of the trial underwent serial transvaginal ultrasound assessment of cervical length beginning in the gestational age window from $16+0$ weeks' to $21+6$ weeks' gestation; sonographic screening ended by $22+6$ weeks. If a patient's cervical length shortened to (or was observed on the initial scan to be) $<25 \mathrm{~mm}$, she became eligible for the randomized trial and was assigned to undergo cerclage or to enter a no-cerclage group (Figure 1). This study afforded the opportunity to describe cervical length measurement in women with a pregnancy at high-risk for recurrent preterm birth. Primary outcome data are being analyzed and will be reported soon. Herein we report the natural history of cervical shortening as estimated by measuring cervical length with transvaginal sonography.

Exclusion criteria for the trial included multiple gestation, fetal anomaly, planned cerclage for a clinical diagnosis of cervical insufficiency, and clinically significant chronic medical 
illness or red cell isoimmunization (i.e. conditions which might result in an indicated preterm birth). Project gestational age was based on standard clinical criteria including certain menstrual dates (if available) confirmed or refuted by first or second-trimester sonographic assessment. Amniocentesis was not prescribed in the protocol to routinely assess the microbiology of the amniotic fluid in women whose cervical length shortened to < $25 \mathrm{~mm}$. According to study protocol, patients were routinely screened and treated for $C$. trachomatis \& N. gonorrhoeae; symptomatic bacterial vaginosis was also treated.

More than 60 certified sonologists performed serial cervical length measurements using endovaginal probes, to determine patient eligibility for randomization. Each sonologist was certified for the trial by the primary investigator (J.O.) to ensure uniformity in ultrasound equipment, measurement techniques, completion of forms, and adherence to the study protocol. The serial vaginal scans were scheduled bi-weekly; however, scan frequency was increased to weekly in the event that the observed cervical length was $25-29 \mathrm{~mm}$.

Specifics of the sonographic evaluation, based on the techniques of Iams and colleagues ${ }^{13}$, are described by Owen and colleagues ${ }^{5}$. Briefly, the cervical length at each visit was measured along a closed endocervical canal, where minimal degrees of apparent dilation (i.e. echolucency along the entire canal) less than $5 \mathrm{~mm}$ were considered closed. Fundal pressure was also applied for 30 seconds as a provocative maneuver, and each scan included an evaluation period of at least 5 minutes to detect spontaneously occurring cervical shortening. The shortest cervical length for each examination was defined as that observed with either spontaneously or fundal pressure-induced dynamic shortening. Consistent with previous reports ${ }^{5,13}$ managing physicians were blinded to the results of the scan, except in cases of fetal death, complete placenta previa, or oligohydramnios. Because the trial utilized a non-blinded intervention, managing physicians were also not blinded to cervical length shortening $<25 \mathrm{~mm}$. Women whose shortest cervical length was $<25 \mathrm{~mm}$ at any evaluation, up to a maximum gestational age of $22+6$ weeks, were eligible for random assignment to receive cerclage or to enter a no-cerclage group. Women whose cervical length was at least $25 \mathrm{~mm}$ by $22+6$ weeks were not eligible for entry into the randomized phase of the trial and underwent no further prerandomization scans.

Complete obstetric histories of each patient were recorded on the screening forms, and events surrounding the prior pregnancies were verified by maternal chart review in nearly all cases. In rare cases, the patient's verbal history would suffice, if records were unavailable. Women with reported spontaneous preterm birth $<2 \mathrm{Kg}$ remained eligible for the trial. In one case, the gestational age of a prior preterm birth was unknown. Based on the reported birth weight, the gestational age was estimated with the national fetal growth curve of Alexander and colleagues ${ }^{14}$. All prior deliveries $\geq 17+0$ weeks were considered as births for the purpose of the trial, and were further classified as to whether it was due to spontaneous causes, versus indicated for maternal-fetal complications. All women in this secondary analysis had experienced at least one prior spontaneous preterm birth at $17+0$ to $33+6$ weeks' gestation. For women who had more than one prior birth, we considered both the gestational age of the earliest preterm birth and also the gestational age of the birth most proximate to trial enrollment (i.e. the most recent birth). In one instance the gestational age of the earliest preterm birth for a woman with multiple prior preterm births was 16 weeks; this is included in the analysis.

For the purposes of this investigation, mid-trimester preterm births were defined as those occurring between $17+0$ and $23+6$ weeks' based on the project gestational age. Separate analyses included women stratified by mid-trimester preterm births ( $<24$ weeks) versus later preterm births (24-33 weeks) and considered both the earliest prior spontaneous preterm birth and also the most recent birth gestational age (which may or may not have 
been preterm). The primary outcome was the time to event (in gestational weeks) where the event of interest was defined as cervical length shortening to $<25 \mathrm{~mm}$ by $22+6$ weeks. If cervical shortening was not observed, then that patient record was considered censored for the survival analysis.

The Kaplan-Meier method was used to estimate time-to-cervical length shortening survivor functions for the two strata, and their equality was tested with the log-rank test. Select baseline characteristics were compared across the two strata. Group differences were tested with chi-square tests for categorical measures and included a relative risk (RR) and 95\% confidence interval (CI). Generalized linear models and the nonparametric Wilcoxon test were used for continuous measures. Cox proportional hazards regression was used to determine a hazard ratio (HR) and corresponding 95\% CI. Baseline characteristics determined to be unequal in the two groups were considered as potential covariates in a multivariable Cox model. Continuous variables are depicted as a mean and standard deviation or a median and interdecile range. An alpha level of .05 was selected to define the rejection region for statistical significance. SAS (SAS Institute, Cary, NC) version 9.1 was utilized for all statistical analyses.

\section{RESULTS}

We analyzed 1014 complete records of high-risk women that met the preterm eligibility requirements and underwent serial vaginal sonography. Scans were initiated at a median gestational age of 17 weeks and the patients underwent a median of 2 serial scans (range: 17) before cervical length shortening or censoring occurred. In all, 318 (31\%) women developed cervical length shortening $<25 \mathrm{~mm}$ by their final scheduled visit.

Stratifying by earliest prior preterm birth, 331 women were included in the mid-trimester group and 683 were included in the later preterm group. The mean gestational age of the earliest prior preterm birth was $20.3 \pm 1.8$ weeks in the mid-trimester group versus $28.7 \pm$ 2.9 weeks in the later preterm group. The difference in the number experiencing cervical length shortening in the mid-trimester group $(\mathrm{n}=149,45 \%)$ as compared to the later preterm group $(n=169,25 \%)$ was statistically significant $(R R=1.8 ; 95 \% C I=1.5,2.2 ; \mathrm{p}<0.0001)$. In addition, the time to cervical length shortening was shorter for women in the midtrimester group (log-rank test $\mathrm{p}<0.0001$; Figure 2). The unadjusted Cox model confirmed a significant relationship $(\mathrm{HR}=2.2 ; 95 \% \mathrm{CI}=1.8,2.8 ; \mathrm{p}<0.0001)$.

Selected characteristics are summarized in Table 1 . Statistically significant differences were found for the following baseline measures: race/ethnicity ( $\mathrm{p}<0.01)$, BMI $(\mathrm{p}<0.0001)$, prior induced abortion ( $p=0.03)$, and GA at first vaginal sonogram ( $<<0.0001)$. A multivariable Cox proportional hazard model included covariates for race/ethnicity, cigarette use, cervicovaginal microbiology, maternal age and BMI, induced abortion history, GA at first ultrasound, and number of prior births (Table 1) was considered. Using backward selection, a parsimonious Cox proportional hazards model including only statistically significant predictors was achieved. Holding other covariates fixed, women whose earliest prior preterm birth was in the mid-trimester demonstrated a $\mathrm{HR}$ of cervical length shortening twice that $(\mathrm{HR}=2.0 ; 95 \% \mathrm{CI}=1.6,2.5 ; \mathrm{p}<0.0001)$ of the later preterm group. An increased hazard ratio for cervical shortening $(\mathrm{HR}=2.1)$ was also observed for African American women as compared to Caucasian women, who served as the referent group in the model. Women of the other race/ethnicities were statistically similar to the Caucasian group with regard to their rate of cervical shortening. Induced abortion history $(\mathrm{HR}=1.5)$, number of prior births $(\mathrm{HR}=0.9)$, and enrollment $\mathrm{GA}(\mathrm{HR}=0.8)$ also remained in the final model as significant predictors. 
Similar results were seen when stratifying the women by the gestational age of the most recent birth, although there were fewer women in the mid-trimester group $(\mathrm{n}=238)$ and more in the later gestational age group $(n=776)$. Note here that not all of these most recent births were preterm. The mean gestational age of the most recent birth was $20.4 \pm 1.8$ weeks in the mid-trimester group versus $32.0 \pm 5.2$ weeks in the later gestational age group. A higher proportion of women experienced cervical length shortening in the mid-trimester group $(\mathrm{n}=123,52 \%)$ versus the later gestational age group $(\mathrm{n}=195,25 \% ; \mathrm{RR}=2.1 ; 95 \% \mathrm{CI}=1.7$, 2.4; $\mathrm{p}<0.0001)$. As before, the interval to cervical length shortening was shorter for women in the mid-trimester group (log-rank test $\mathrm{p}<0.0001$; Figure 3$)$ and confirmed in the unadjusted Cox model $(\mathrm{HR}=2.8 ; 95 \% \mathrm{CI}=2.2,3.5 ; \mathrm{p}<0.0001)$.

Table 2 summarizes characteristics, with statistically significant differences found for race/ ethnicity $(\mathrm{p}=0.02)$, presence of bacterial vaginosis $(\mathrm{p}=0.03)$, maternal age $(\mathrm{p}=0.03)$, number of prior births $(\mathrm{p}<0.0001)$, and BMI $(\mathrm{p}<0.0001)$. A multivariable Cox proportional hazards model with covariates for race/ethnicity, cigarette use, cervicovaginal microbiology, maternal age and BMI, induced abortion history, GA at first ultrasound, and number of prior births was considered. In the final model women whose most recent prior birth was in the mid-trimester demonstrated a hazard of cervical length shortening over twice that $(\mathrm{HR}=2.5 ; 95 \% \mathrm{CI}=2.0,3.1, \mathrm{p}<0.0001)$ of the later group and African American women experienced a rate over twice that of Caucasian women $(\mathrm{HR}=2.1)$. Induced abortion history $(\mathrm{HR}=1.4)$, and enrollment $\mathrm{GA}(\mathrm{HR}=.85)$ also remained significant in the final Cox model.

\section{DISCUSSION}

High-risk women with prior very preterm, mid-trimester birth histories ( $<24$ weeks) are at significantly higher risk of cervical length shortening than women with later births, preterm or otherwise. When based on the earliest prior preterm birth gestational age history, the hazard for earlier cervical shortening $<25 \mathrm{~mm}$ in women with prior mid-trimester birth is twice that observed in women with a later preterm birth history. Likewise, when based on the most recent birth history, women with a mid-trimester preterm birth are at over twice the hazard of early shortening compared to those with a later birth. Furthermore, high-risk African American women experience cervical length shortening at twice the rate of women of other race/ethnicities, consistent with their recognized disproportionally higher preterm birth rates ${ }^{4,15}$. Based on earlier published research, the combination of mid-trimester cervical shortening and a prior early preterm birth indicates an appreciable risk of midtrimester delivery 8,16 .

We believe that this represents the largest investigation to date of the natural history of cervical length in a population of multiparous women, homogeneous for the single most important historic risk factor for spontaneous preterm birth. Although this represents a secondary analysis of data from a randomized clinical trial, this was a planned analysis and represents sonographic data that was not revealed to managing physicians unless the cervical length shortened to $<25 \mathrm{~mm}$, the action point for the randomly assigned cerclage intervention. Nevertheless, the study is not without limitations. We purposefully excluded women with co-morbid medical conditions because of their increased risk of indicated preterm birth, which may have confounded the clinical trial's primary outcome. We also did not include women with clinically defined cervical insufficiency that may have benefitted from prophylactic ${ }^{17}$ or ultrasound-indicated cerclage ${ }^{18}$. Perhaps the largest quantitative limitation stems from the specific trial methodology which necessarily censored the data in 2 ways. First, by design, randomization had to be performed by 23 weeks' gestation, as the trial investigators recommended that mid-trimester surgical interventions be completed by this time. Thus, it is possible, or even likely that some women would have continued to 
shorten, thus potentially underestimating the observed rates. The cervical length data were also censored by the trial's entry criteria of cervical length $<25 \mathrm{~mm}$, which while somewhat arbitrary, has been utilized by many other investigators to define a very high-risk population ${ }^{18-20}$. Here again, our shortest observed cervical length (population median $=30$ $\mathrm{mm}$ ) was also likely an underestimate. Lastly, for logistic reasons, we scheduled the sonograms every 2 weeks and therefore may have missed some cases of cervical shortening if the end of the observational window arrived before the next scheduled scan. In spite of these potential limitations this was a collaborative effort, comprising 16 clinical centers around the U.S. and represents the work of over 60 certified sonologists and numerous research nurse coordinators. Data were collected prospectively on standardized data forms, while our data coordinating center performed a wide range of edits to identify and correct possible data collection/entry errors. Considering also the very large study sample, we believe that our findings are clinically important, robust and generalizable to other similar at-risk populations.

\section{Acknowledgments}

Financial disclosure: This Study was supported by grant U01 HD039939 from the Eugene Kennedy Shriver National Institute of Child Health and Human Development

Other members of the Vaginal Ultrasound Cerclage Trial Consortium:

University of Alabama at Birmingham: John C. Hauth, MD

University of Texas, Houston: Susan Ramin, MD

Evanston Hospital: Richard Silver, MD

University of Tennessee, Memphis: Robert Egerman, MD

Northwest Perinatal Center: Mark Tomlinson, MD

Wilford Hall Medical Center: Mike Gordon, MD

University of Cincinnati: Helen How, MD

University of Oklahoma: Eric Knudtson, MD

\section{REFERENCES}

1. Martin JA, Kung HC, Mathews TJ, Hoyert DL, Strobino DM, Guyer B, Sutton SR. Annual Summary of Vital Statistics: 2006. Pediatrics. 2008; 121:788-801. [PubMed: 18381544]

2. Goldenberg RL, Rouse DJ. Prevention of premature birth. NEJM. 1998; 339:313-320. [PubMed: 9682045]

3. Spong CY. Prediction and prevention of recurrent spontaneous preterm birth. Obstet Gynecol. 2007; 110:405-415. [PubMed: 17666618]

4. McManemy J, Cooke E, Amon E, Leet T. Recurrence risk for preterm delivery. Am J Obstet Gynecol. 2007; 196:576.e1-576.e7. [PubMed: 17547902]

5. Owen J, Yost N, Berghella V, Thom E, Swain M, Dildy GA, Miodovnik M, Langer D, Sibai BM, McNellis D. for the National Institute for Child Health and Human Development Maternal Fetal Medicine Unit Network. Mid-trimester endovaginal sonography in women at high risk for spontaneous preterm birth. JAMA. 2001; 286:1340-1348. [PubMed: 11560539]

6. Berghella V, Tolosa JE, Kuhlman K, Weiner S, Bolognese RJ, Wapner RJ. Cervical ultrasonography compared with manual examination as a predictor of preterm delivery. Am J Obstet Gynecol. 1997; 177:723-730. [PubMed: 9369810] 
7. Andrews WW, Copper R, Hauth JC, Goldenberg RL, Neely C, DuBard M. Second-trimester cervical ultrasound: associations with increased risk for recurrent early spontaneous delivery. Obstet Gynecol. 2000; 95:222-226. [PubMed: 10674583]

8. Owen J, Yost N, Berghella V, et al. Can shortened mid-trimester cervical length predict very early spontaneous preterm birth? Am J Obstet Gynecol. 2004; 191:298-303. [PubMed: 15295382]

9. Iams JD, Johnson FF, Sonek J, Sachs L, Gebauer C, Samuels P. Cervical competence as a continuum: A study of ultrasonographic cervical length and obstetric performance. Am J Obstet Gynecol. 1995; 172:1097-1106. [PubMed: 7726247]

10. Romero R, Mazor M, Munoz H, Gomez R, Galasso M, Sherer DM. The preterm labor syndrome. Ann HY Acad Sci. 1994; 734:414-429.

11. Romero R, Espinoza J, Erez O, Hassan S. The role of cerclage in obstetric practice: can the patient who could benefit from this procedure be identified? Am J Obstet Gynecol. 2006; 194:1-9. [PubMed: 16389003]

12. Owen J, Iams JD, Hauth JC. Vaginal sonography and cervical incompetence. Am J Obstet Gynecol. 2003; 188:586-596. [PubMed: 12592276]

13. Iams JD, Goldenberg RL, Meis PJ, Mercer BM, Moawad A, Das A, Thom E, McNellis D, Copper RL, Johnson F, Roberts JM. for the National Institute of Child Health and Human Development Maternal Fetal Medicine Unit Network. The length of the cervix and the risk of spontaneous premature delivery. N Engl J Med. 1996; 334:567-572. [PubMed: 8569824]

14. Alexander GR, Himes JH, Kaufman RB, Mor J, Kogan M. A United States national reference for fetal growth. Obstet Gynecol. 1996; 87:163-168. [PubMed: 8559516]

15. Kista ZAF, Palomar L, Lee KA, Boslaugh SE, Wangler MF, Cole FS, DeBaun MR, Muglia LJ. Racial disparity in the frequency of recurrence of preterm birth. Am J Obstet Gynecol. 2007; 196:131.e1-131.e6. [PubMed: 17306652]

16. Iams JD, Goldenberg RL, Mercer BM, Moawad A, Das A, Thom E, Meis PJ, McNellis D, Caritis SN, Miodovnik M, Menard MK, Thurnau GR, Bottoms SF, Roberts JM. for the National Institute of Child Health and Human Development Maternal Fetal Medicine Unit Network. The Preterm Prediction Study: Recurrence risk of spontaneous preterm birth. Am J Obstet Gynecol. 1998; 178:1035-1040. [PubMed: 9609580]

17. Anonymous. American College of Obstetricians and Gynecologists. Cervical Insufficiency. Practice bulletin Number 48. 2003 November.

18. Althuisius SM, Dekker GA, Hummel P, Bekedam DJ, van Geijn HP. Final results of the cervical incompetence prevention randomized cerclage trial (CIPRACT): Therapeutic cerclage with bed rest versus bed rest alone. Am J Obstet Gynecol. 2001; 185:1106-1112. [PubMed: 11717642]

19. Rust OA, Atlas RO, Reed J, van Gaalen J, Balducci J. Revisiting the short cervix detected by transvaginal ultrasound in the second trimester: Why cerclage may not help. Am J Obstet Gynecol. 2001; 185:1098-1105. [PubMed: 11717641]

20. Berghella V, Odibo AO, Tolosa JE. Cerclage for prevention of preterm birth in women with a short cervix found on transvaginal ultrasound: A randomized trial. Am J Obstet Gynecol. 2004; 191:1311-1317. [PubMed: 15507959] 


\section{Vaginal Ultrasound Cerclage Trial Flowchart}

Patient enrolls for care; project gestational age established.

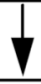

Research nurse screens history and confirms prior spontaneous preterm birth $<34$ +0 weeks by chart review (if chart unavailable, confirms history of spontaneous birth and weight $<2 \mathrm{Kg}$ ). Obstetric providers confirm that prophylactic cerclage not indicated. No exclusion criteria present confirmed.

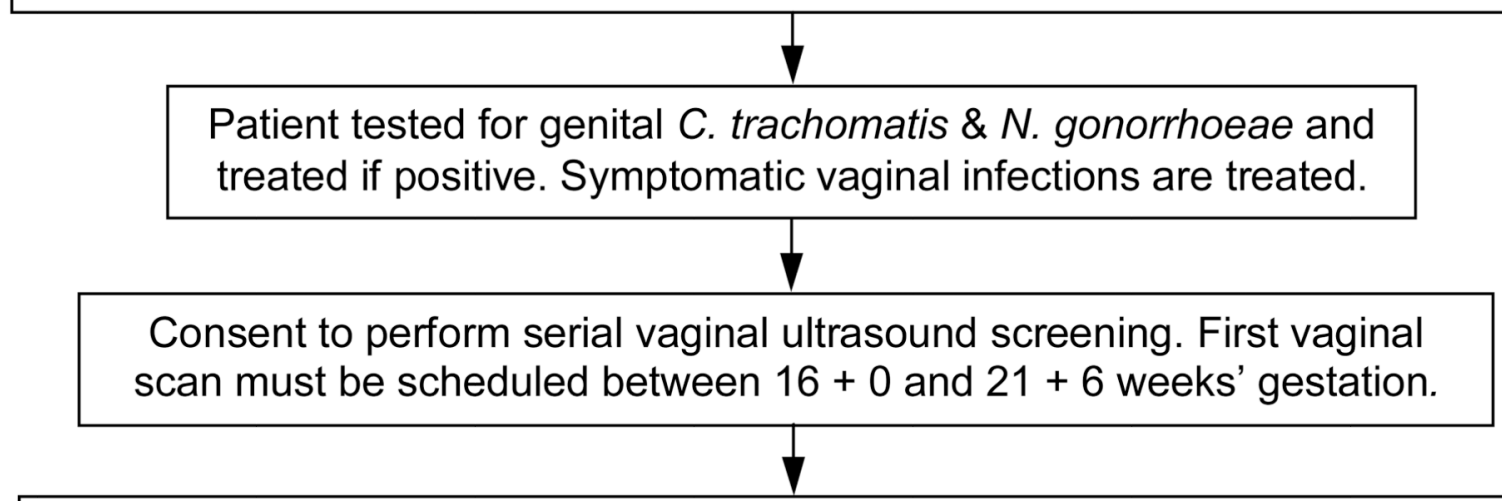

If cervical length $25-29 \mathrm{~mm}$, scan frequency increased from biweekly to weekly

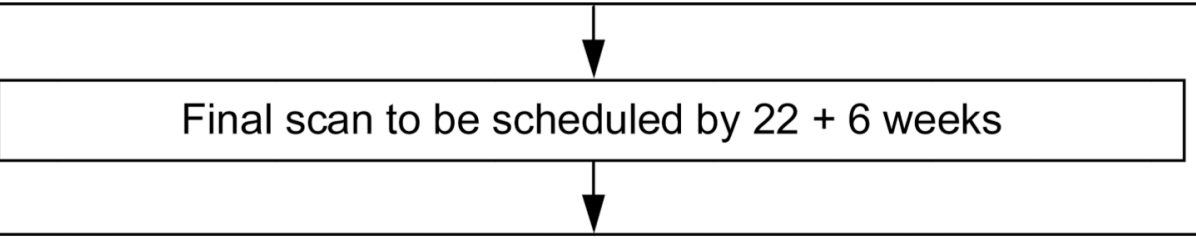

If cervical length $<25 \mathrm{~mm}$, consent and randomize to Cerclage or No-Cerclage group.

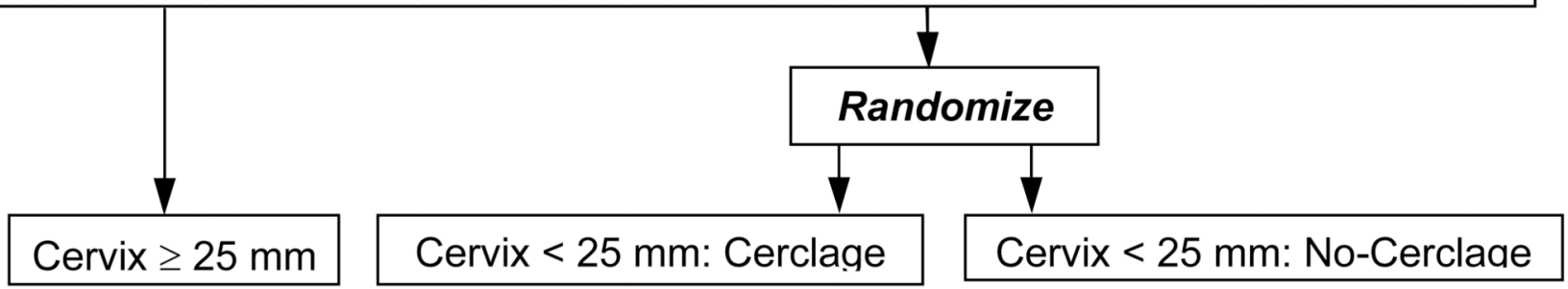

Figure 1.

Diagram of patient events up to randomization. 


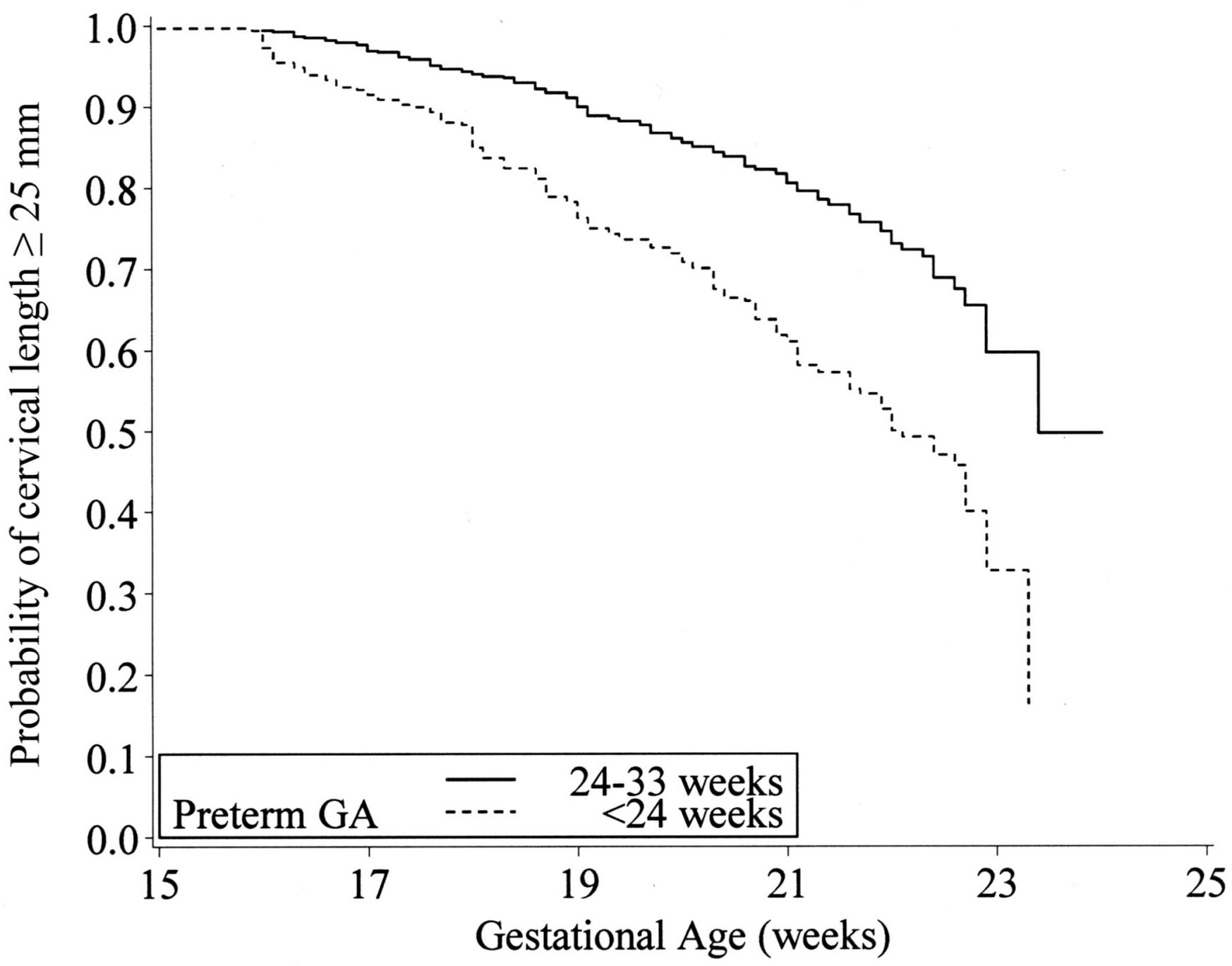

Figure 2.

Kaplan-Meier survival curve estimates of proportion of women not experiencing cervical length shortening prior to 23 weeks' gestation. Women stratified by gestational age group of their earliest preterm birth $(\mathrm{p}<0.0001)$. 


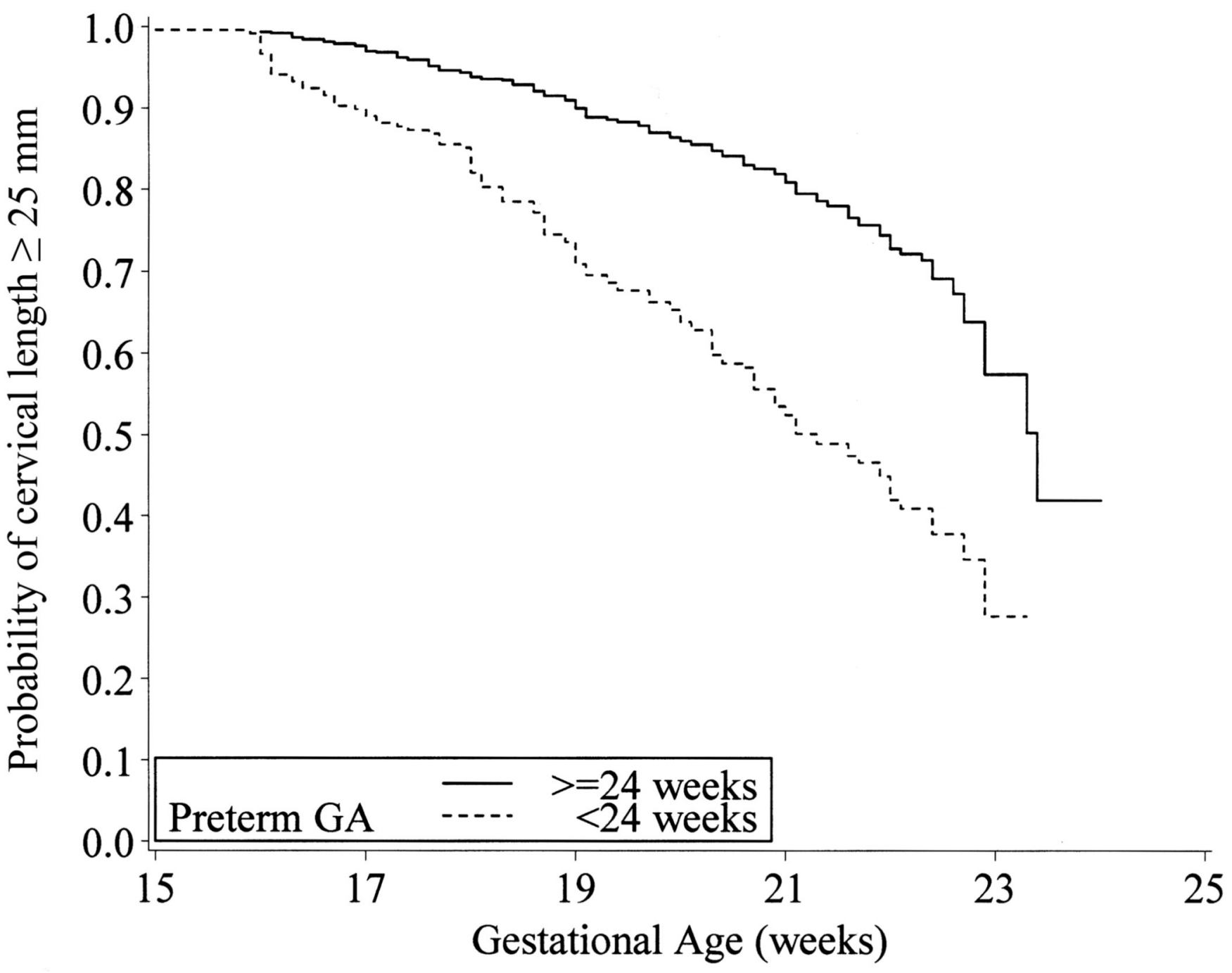

Figure 3.

Kaplan-Meier survival curve estimates of the proportions of women not experiencing cervical length shortening prior to 23 weeks' gestation. Women stratified by gestational age group of most recent preterm birth $(\mathrm{p}<0.0001)$. 
TABLE 1

Selected characteristics of the 1014 high-risk women who entered mid-trimester vaginal ultrasound screening stratified by gestational age of earliest prior spontaneous preterm birth.

\begin{tabular}{|c|c|c|c|}
\hline & $\begin{array}{c}\text { Mid-trimester } \\
\text { Group } \\
(\mathbf{n}=\mathbf{3 3 1})\end{array}$ & $\begin{array}{c}\text { Later Preterm } \\
\text { Group } \\
(\mathbf{n}=\mathbf{6 8 3})\end{array}$ & $\mathbf{p}$ \\
\hline \multicolumn{4}{|l|}{ Race/Ethnicity } \\
\hline Black (non-Hispanic) & $48.6 \%$ & $36.5 \%$ & \\
\hline White (non-Hispanic) & $19.6 \%$ & $18.2 \%$ & \\
\hline Hispanic & $20.5 \%$ & $27.5 \%$ & \\
\hline Asian & $0.6 \%$ & $1.5 \%$ & \\
\hline Other & $10.6 \%$ & $16.4 \%$ & $<0.01$ \\
\hline Cigarette use & $15.4 \%$ & $13.8 \%$ & 0.48 \\
\hline \multicolumn{4}{|l|}{ Cervicovaginal microbiology } \\
\hline Chlamydia & $3.9 \%$ & $3.5 \%$ & 0.74 \\
\hline Trichomonas & $2.7 \%$ & $3.1 \%$ & 0.75 \\
\hline Bacterial vaginosis & $9.1 \%$ & $7.0 \%$ & 0.25 \\
\hline Maternal age (years) & $26.4(5.2)$ & $26.8(5.4)$ & 0.29 \\
\hline Body mass index $\left(\mathrm{Kg} / \mathrm{m}^{2}\right)$ & $30.6(7.8)$ & $28.3(6.8)$ & $<0.0001$ \\
\hline Number of prior births $(\mathrm{N})$ & $2(1,4)^{*}$ & $2(1,4)^{*}$ & .25 \\
\hline At least one prior induced abortion & $15 \%$ & $10 \%$ & 0.03 \\
\hline GA of first vaginal sonogram (wks) & $17.0(16.0,19.1)^{*}$ & $17.6(16.1,19.7)^{*}$ & $<0.0001$ \\
\hline GA of shortest observed cervical length (wks) & $20.2(2.0)$ & $20.9(1.7)$ & $<0.0001$ \\
\hline Shortest observed cervical length (mm) & $27.0(10.5)$ & $31.3(9.4)$ & $<0.0001$ \\
\hline Total number of vaginal sonograms $(\mathrm{N})$ & $2(1,4)^{*}$ & $3(1,4)^{*}$ & 0.08 \\
\hline
\end{tabular}

* Median and interdecile range; $\mathrm{GA}=$ gestational age 
TABLE 2

Selected characteristics of the 1014 high-risk women who entered mid-trimester vaginal ultrasound screening stratified by gestational age of most recent birth.

\begin{tabular}{|c|c|c|c|}
\hline & $\begin{array}{c}\text { Mid-trimester } \\
\text { Group } \\
(\mathbf{n}=\mathbf{2 3 8})\end{array}$ & $\begin{array}{c}\text { Later Gestational } \\
\text { Age Group } \\
(\mathbf{n}=\mathbf{7 7 6})\end{array}$ & $\mathbf{p}$ \\
\hline \multicolumn{4}{|l|}{ Race/Ethnicity } \\
\hline Black (non-Hispanic) & $48.3 \%$ & $38.0 \%$ & \\
\hline White (non-Hispanic) & $19.8 \%$ & $18.3 \%$ & \\
\hline Hispanic & $20.6 \%$ & $26.7 \%$ & \\
\hline Asian & $0.4 \%$ & $1.4 \%$ & \\
\hline Other & $10.9 \%$ & $15.6 \%$ & 0.02 \\
\hline Cigarette use & $13.5 \%$ & $14.6 \%$ & 0.67 \\
\hline \multicolumn{4}{|l|}{ Cervicovaginal microbiology } \\
\hline Chlamydia & $4.6 \%$ & $3.4 \%$ & 0.36 \\
\hline Trichomonas & $3.4 \%$ & $2.8 \%$ & 0.68 \\
\hline Bacterial vaginosis & $10.9 \%$ & $6.7 \%$ & 0.03 \\
\hline Maternal age (y) & $26.0(5.3)$ & $26.9(5.3)$ & 0.03 \\
\hline Body mass index $\left(\mathrm{Kg} / \mathrm{m}^{2}\right)$ & $30.8(7.7)$ & $28.5(6.9)$ & $<0.0001$ \\
\hline Number of prior births $(\mathrm{N})$ & $1(1,3)^{*}$ & $2(1,4)^{*}$ & $<0.0001$ \\
\hline At least one prior induced abortion & $14 \%$ & $11 \%$ & 0.18 \\
\hline GA of first vaginal sonogram (wks) & $17.0(16.0,19.1)^{*}$ & $17.6(16.1,19.7)^{*}$ & $<0.0001$ \\
\hline GA at cervical length shortening or censoring (wks) & $19.9(2.1)$ & $20.9(1.7)$ & $<0.0001$ \\
\hline Shortest observed cervical length (mm) & $25.6(10.4)$ & $31.2(9.5)$ & $<0.0001$ \\
\hline Total number of vaginal sonograms $(\mathrm{N})$ & $2(1,4)^{*}$ & $3(1,4)^{*}$ & $<0.01$ \\
\hline
\end{tabular}

Median and interdecile range; $\mathrm{GA}=$ gestational age 